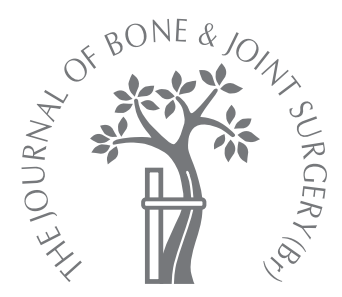

\title{
Use of the reverse shoulder prosthesis for the treatment of failed hemiarthroplasty in patients with glenohumeral arthritis and rotator cuff deficiency
}

\section{J. C. Levy, \\ N. Virani, \\ D. Pupello, \\ M. Frankle}

From Florida

Orthopaedic

Institute, Florida, USA
J. C. Levy, MD, Orthopaedic Surgeon

Orthopaedic Institute at Holy Cross, Fort Lauderdale, 33308 Florida, USA.

N. Virani, MD, Research Fellow

D. Pupello, BS, MBA, Consultant Researcher, Research Manager

M. Frankle, MD, Orthopaedic Surgeon

Florida Orthopaedic Institute, 13020 Telecom Parkway North, Temple Terrace, Florida 33637 USA.

Correspondence should be sent to Dr M. Frankle; e-mail: dpupello@floridaortho.com

(C)2007 British Editorial Society of Bone and Joint Surgery doi:10.1302/0301-620X.89B2. $18161 \$ 2.00$

$J$ Bone Joint Surg [Br] 2007;89-B:189-95. Received 22 May 2006; Accepted after revision 1 September 2006

\begin{abstract}
We report the use of the reverse shoulder prosthesis in the revision of a failed shoulder hemiarthroplasty in 19 shoulders in 18 patients ( 7 men, 11 women) with severe pain and loss of function. The primary procedure had been undertaken for glenohumeral arthritis associated with severe rotator cuff deficiency.

Statistically significant improvements were seen in pain and functional outcome. After a mean follow-up of 44 months (24 to 89), mean forward flexion improved by $26.4^{\circ}$ and mean abduction improved by $35^{\circ}$. There were six prosthesis-related complications in six shoulders $(32 \%)$, five of which had severe bone loss of the glenoid, proximal humerus or both. Three shoulders (16\%) had non-prosthesis related complications.

The use of the reverse shoulder prosthesis provides improvement in pain and function for patients with failure of a hemiarthroplasty for glenohumeral arthritis and rotator cuff deficiency. However, high rates of complications were associated with glenoid and proximal humeral bone loss.
\end{abstract}

Hemiarthroplasty is often undertaken in the treatment of patients with glenohumeral arthritis and rotator cuff deficiency. ${ }^{1-6}$ The results in these patients vary in terms of function and pain relief. $1,2,5,7,8$ Occasionally, patients continue to have symptoms which may be due to glenohumeral instability ${ }^{6}$ or erosion of the glenoid or acromion, or both. ${ }^{9}$ So far, there has been no reliable treatment for these patients. The design of the reverse prosthesis permits treatment and we have reported the successful use of this design with reliable improvement in both pain and function. ${ }^{10}$

Here we report the results of the reverse shoulder prosthesis (Encore Medical Corporation, Austin, Texas) in revision surgery for patients with an unsatisfactory outcome from a hemiarthroplasty undertaken for a rotator cuff dysfunction in the presence of glenohumeral arthritis. To our knowledge, this is the first such report in the literature.

\section{Patients and Methods}

Between April 1998 and June 2004, 19 shoulders in 18 patients ( 7 men, 11 women) with severe pain and loss of function following a previous hemiarthroplasty for glenohumeral arthritis associated with severe rotator cuff deficiency were treated with single-stage revision to a reverse shoulder prosthesis.
The mean age of the patients at the time of revision was 72 years (56 to 83). Of the 19 shoulders, 15 had been treated with a hemiarthroplasty alone a mean of 45 months (29 to 69) previously, and four with a hemiarthroplasty and tendo Achillis allograft interposition arthroplasty a mean of 45 months (5 to 78) previously. All the patients had failed at attempted conservative management, including physiotherapy and cortisone injections before being offered revision surgery. No patient died or was lost to follow-up.

Operative technique. Under general anaesthesia with a supplementary scalene nerve block the patient was positioned semi-recumbent with the head elevated. An extended deltopectoral approach was used, and up to twothirds of the pectoralis major tendon was released from its humeral insertion. The subdeltoid, subacromial and subcoracoid spaces were developed and released. This dissection was often prolonged because of thick scar formation. The axillary nerve was identified, and a tug test was performed. The integrity of the rotator cuff was assessed. If the subscapularis tendon was intact, it was released subperiosteally from the proximal humerus, allowing atraumatic dislocation of the hemiarthroplasty with gentle external rotation and extension of the arm. If the subscapularis was not intact, it did not need to be released for 
exposure. The shoulder capsule was released circumferentially from the humeral neck. If the prosthesis was modular, the humeral head was separated from the Morse taper of the stem using a forked wedge disimpactor.

Removal of the hemiarthroplasty was performed in a stepwise fashion. Circumferential exposure of the proximal portion was established, with the removal of all soft tissue, bone ingrowth and cement from around the humeral head, collar and fins of the prosthesis aided by a combination of osteotomes and a high-speed burr. In cases of proximallycoated stems, a thin flexible osteotome was used to create a space between the prosthesis and the bone. Once the medial neck and fins were exposed, the arm was elevated to $90^{\circ}$ of abduction and placed on a Mayo stand. A punch was placed on the edge on the medial neck of the prosthesis, allowing cautious hammer blows to be delivered to the prosthesis. Once it had been dislodged from the cortical bone (14 cases) or cement mantle (five cases), the arm was placed into full adduction and extraction of the prosthesis was completed.

After the hemiarthroplasty was removed, the subscapularis was tagged for future repair and heterotopic ossification and osteophytes were resected. When present, the previous cement mantle was left intact. Sequential handheld diaphyseal reamers were used to prepare the intramedullary canal and a trial broach was introduced until it was seated just distal to the level of the resected humeral neck. The proximal humeral metaphysis was then reamed using metaphysical reamers that fit into the humeral broach. When this stage was completed the glenoid was exposed by a thorough $360^{\circ}$ peri-glenoid capsular release. A $2.5 \mathrm{~mm}$ diameter drill was passed to a minimum depth of $25 \mathrm{~mm}$ into the glenoid. A $6.5 \mathrm{~mm}$ tap was then advanced into this hole. A convex cannulated reamer was engaged over the shaft of the tap to allow controlled reaming of the glenoid such that a conforming surface of bleeding bone was exposed. The tap was removed, and the fixed-angle threaded glenoid baseplate was then screwed on to the prepared glenoid; at least $6.8 \mathrm{Nm}$ of torque was applied for engagement. Additional $3.5 \mathrm{~mm}$ peripheral fixation screws were then passed through the glenoid baseplate. Depending on the extent of the soft-tissue contracture, the stability of the joint and resulting range of movement, one of two glenosphere sizes was chosen, $32 \mathrm{~mm}$ neutral or $32 \mathrm{~mm}$ $(-4)$, with the exception of one case where a $36 \mathrm{~mm}$ neutral size was selected. The chosen glenosphere was attached to the baseplate by a Morse taper. After reduction with the humeral broach and with a trial polyethylene component in place, the appropriate size of humeral implant that would allow a $2 \mathrm{~mm}$ circumferential cement mantle was selected. The definitive stem was then cemented into the canal or into the prepared pre-existing cement mantle. The reduction was checked for stability (especially in abduction, extension and internal rotation), and achievement of full passive elevation was confirmed. The subscapularis was reattached through drill-holes into the native proximal humerus, followed by a routine closure using no. 2 braided polyester sutures.

Post-operative rehabilitation. A shoulder brace was worn for six weeks to restrict movement. Passive pendular exercises were started the day after surgery under the direction of a physiotherapist. After the first six weeks, the patient was managed with a sling and began gentle active and active-assisted activities. Resisted exercises were delayed until 12 weeks post-operatively.

Pre- and post-operative clinical assessment. Several validated scoring instruments were used to assess the patients clinically. ${ }^{11}$ Patients completed forms for the American Shoulder and Elbow Surgeons assessment ${ }^{11}$ for pain and function, a visual analogue scale (VAS) for pain and function where 0 is no pain or limitation of function, and 10 is severe pain and severe loss of function, and a subjective rating of overall satisfaction. Patients were asked to indicate their personal satisfaction with the outcome of the surgery as 'dissatisfied', 'satisfied', 'good', or 'excellent'. An orthopaedic surgeon (JCL) not involved in the treatment measured the range of movement pre- and post-operatively using a goniometer while digital clinical videos were played back on a computer. Pre- and post-operative flexion, abduction and external rotation data were available for all patients.

Radiological assessment. All patients were evaluated on initial presentation with anteroposterior, axillary, $40^{\circ}$ posterior oblique with external rotation of the humerus, and $40^{\circ}$ posterior oblique with internal rotation of the humerus radiographs. For each patient three sets of radiographs were evaluated retrospectively: radiographs prior to initial revision to reverse shoulder prosthesis, immediate postoperative radiographs and those taken at the most recent follow-up.

Radiographs taken prior to the revision were assessed for joint position, degree and position of erosion of the glenoid, degree erosion of the acromion, the presence of a fracture of the acromion, and evidence of loosening of the hemiarthroplasty. In seven shoulders, computed tomography (CT) scans which had been performed to assist in pre-operative planning were available and were used to confirm these findings.

Joint position was evaluated with regard to direction and amount of translation of the centre of the hemiarthroplasty relative to the centre of the glenoid. The incongruence was classified using a modified version of Antuna et $\mathrm{al}^{12}$ as none, mild $(<25 \%$ translation), moderate $(25 \%$ to $50 \%$ translation), and severe (> 50\% translation).

Erosion of the glenoid was graded according to a classification system of glenoid bone loss described by Antuna et $\mathrm{al}^{12}$ as central, peripheral (anterior, anterosuperior or posterior), or combined (central and peripheral), and its severity was classified as mild (less than one-third of glenoid rim), moderate (one-third to two-thirds) or severe (more than two-thirds). The severity of acromial erosion was classified as none, mild ( $<25 \%$ of acromion), moderate $(25 \%$ to $50 \%)$, and severe $(>50 \%) .^{12}$ 
Table I. Clinical results using the American Shoulder and Elbow Surgeons (ASES) and visual analogue scale (VAS) scores as well as range of movement (mean, range), pre-operatively and at a mean of 44 months (24 to 89 ) post-operatively

\begin{tabular}{lcrr}
\hline & Pre-operative & Post-operative & $\begin{array}{c}\text { p-value } \\
\text { (t-test) }\end{array}$ \\
\hline Total ASES & $29.1(10$ to 57.5$)$ & $61.2(17.5$ to 95$)$ & $<0.0001$ \\
VAS pain & $7.3(3.5$ to 10$)$ & $2.5(0$ to 9$)$ & $<0.0001$ \\
VAS function forward & $2.7(0$ to 5$)$ & $5.5(0$ to 10$)$ & 0.0082 \\
Flexion $\left(^{\circ}\right)$ & $49.7(30$ to 90$)$ & $76.1(0$ to 150$)$ & 0.0062 \\
Abduction $\left(^{\circ}\right)$ & $42.2(0$ to 60$)$ & $77.2(30$ to 150$)$ & 0.0005 \\
\hline
\end{tabular}

Table II. Pre-operative radiological analysis and reverse shoulder components selected for revision

\begin{tabular}{|c|c|c|c|c|c|c|c|c|c|c|c|}
\hline \multirow[b]{2}{*}{ Patient } & \multirow[b]{2}{*}{$\begin{array}{l}\text { Interposition } \\
\text { arthroplasty }\end{array}$} & \multirow[b]{2}{*}{ Joint position } & \multirow[b]{2}{*}{$\begin{array}{l}\text { Degree of } \\
\text { glenoid } \\
\text { erosion }\end{array}$} & \multirow[b]{2}{*}{$\begin{array}{l}\text { Location of } \\
\text { peripheral } \\
\text { glenoid wear }\end{array}$} & \multirow[b]{2}{*}{ Loosening } & \multirow[b]{2}{*}{ Cemented } & \multirow[b]{2}{*}{$\begin{array}{l}\text { Acromion } \\
\text { wear }\end{array}$} & \multirow[b]{2}{*}{$\begin{array}{l}\text { Acromion } \\
\text { fracture }\end{array}$} & \multicolumn{3}{|c|}{ Reverse shoulder components } \\
\hline & & & & & & & & & $\begin{array}{l}\text { Gleno- } \\
\text { sphere }\end{array}$ & $\begin{array}{l}\text { Stem } \\
\text { diame- } \\
\text { ter } \\
(\mathrm{mm})\end{array}$ & $\begin{array}{l}\text { Polyethyl- } \\
\text { ene }\end{array}$ \\
\hline 1 & No & $\begin{array}{l}\text { Anterosuperior } \\
\text { severe }\end{array}$ & Moderate & $\begin{array}{l}\text { Anterosupe- } \\
\text { rior }\end{array}$ & No & No & Moderate & No & $\begin{array}{l}36 \mathrm{~mm} \\
\text { neutral }\end{array}$ & 10 & Neutral \\
\hline 2 & Yes & $\begin{array}{l}\text { Superior moder- } \\
\text { ate }\end{array}$ & Moderate & Superior & No & No & None & No & $\begin{array}{l}32 \mathrm{~mm} \\
(-4)\end{array}$ & 8 & Neutral \\
\hline 3 & Yes & $\begin{array}{l}\text { Anterosuperior } \\
\text { moderate }\end{array}$ & Moderate & $\begin{array}{l}\text { Anterosupe- } \\
\text { rior }\end{array}$ & No & No & Mild & No & $\begin{array}{l}32 \mathrm{~mm} \\
(-4)\end{array}$ & 8 & Neutral \\
\hline 4 & No & $\begin{array}{l}\text { Superior moder- } \\
\text { ate }\end{array}$ & Severe & Superior & No & No & None & No & $\begin{array}{l}32 \mathrm{~mm} \\
\text { neutral }\end{array}$ & 8 & Neutral \\
\hline 5 & No & Superior severe & Mild & $\begin{array}{l}\text { Posterosupe- } \\
\text { rior }\end{array}$ & No & No & Severe & Yes & $\begin{array}{l}32 \mathrm{~mm} \\
\text { neutral }\end{array}$ & 6 & Neutral \\
\hline 6 & Yes & $\begin{array}{l}\text { Superior moder- } \\
\text { ate }\end{array}$ & Severe & Superior & No & No & Mild & No & $\begin{array}{l}32 \mathrm{~mm} \\
\text { neutral }\end{array}$ & 8 & $+4 \mathrm{~mm}$ \\
\hline 7 & No & $\begin{array}{l}\text { Anterosuperior } \\
\text { moderate }\end{array}$ & Moderate & $\begin{array}{l}\text { Anterosupe- } \\
\text { rior }\end{array}$ & No & Yes & None & No & $\begin{array}{l}32 \mathrm{~mm} \\
\text { neutral }\end{array}$ & 7 & $+8 \mathrm{~mm}$ \\
\hline 8 & No & $\begin{array}{l}\text { Anterosuperior } \\
\text { severe }\end{array}$ & Severe & Posterior & No & No & Severe & Yes & $\begin{array}{l}32 \mathrm{~mm} \\
\text { neutral }\end{array}$ & 7 & $+4 \mathrm{~mm}$ \\
\hline 9 & No & $\begin{array}{l}\text { Anterosuperior } \\
\text { severe }\end{array}$ & Severe & Superior & No & Yes & Moderate & No & $\begin{array}{l}32 \mathrm{~mm} \\
(-4)\end{array}$ & 6 & Neutral \\
\hline 10 & No & Superior mild & Mild & Superior & No & No & Moderate & Yes & $\begin{array}{l}32 \mathrm{~mm} \\
\text { neutral }\end{array}$ & 6 & Neutral \\
\hline 11 & Yes & $\begin{array}{l}\text { Anterosuperior } \\
\text { severe }\end{array}$ & Severe & $\begin{array}{l}\text { Anterosupe- } \\
\text { rior }\end{array}$ & No & No & Moderate & No & $\begin{array}{l}32 \mathrm{~mm} \\
\text { neutral }\end{array}$ & 6 & Neutral \\
\hline 12 & No & $\begin{array}{l}\text { Anterosuperior } \\
\text { severe }\end{array}$ & Mild & Superior & No & Yes & Moderate & No & $\begin{array}{l}32 \mathrm{~mm} \\
\text { neutral }\end{array}$ & 6 & Neutral \\
\hline 13 & No & $\begin{array}{l}\text { Superior moder- } \\
\text { ate }\end{array}$ & Mild & Superior & No & Yes & Mild & No & $\begin{array}{l}32 \mathrm{~mm} \\
(-4)\end{array}$ & 8 & Neutral \\
\hline 14 & No & Superior severe & Moderate & Superior & No & No & None & No & $\begin{array}{l}32 \mathrm{~mm} \\
\text { neutral }\end{array}$ & 8 & $+4 \mathrm{~mm}$ \\
\hline 15 & No & $\begin{array}{l}\text { Anterosuperior } \\
\text { severe }\end{array}$ & Severe & $\begin{array}{l}\text { Anterosupe- } \\
\text { rior }\end{array}$ & No & No & Severe & No & $\begin{array}{l}32 \mathrm{~mm} \\
\text { neutral }\end{array}$ & 8 & Neutral \\
\hline 16 & No & $\begin{array}{l}\text { Anterosuperior } \\
\text { severe }\end{array}$ & Severe & $\begin{array}{l}\text { Anterosupe- } \\
\text { rior }\end{array}$ & No & No & None & No & $\begin{array}{l}32 \mathrm{~mm} \\
\text { neutral }\end{array}$ & 7 & Neutral \\
\hline 17 & No & Posterior severe & Mild & Posterior & No & No & None & No & $\begin{array}{l}32 \mathrm{~mm} \\
(-4)\end{array}$ & 7 & Neutral \\
\hline 18 & No & $\begin{array}{l}\text { Anterosuperior } \\
\text { mild }\end{array}$ & Mild & $\begin{array}{l}\text { Anterosupe- } \\
\text { rior }\end{array}$ & No & Yes & None & No & $\begin{array}{l}32 \mathrm{~mm} \\
\text { neutral }\end{array}$ & 7 & Neutral \\
\hline 19 & No & Superior severe & Moderate & Superior & No & No & Mild & No & $\begin{array}{l}32 \mathrm{~mm} \\
(-4)\end{array}$ & 7 & Neutral \\
\hline
\end{tabular}

The initial post-operative anteroposterior radiographs were evaluated to determine the degree of proximal humeral bone loss present after reconstruction. This was classified into three groups based on the amount of metaphyseal deficiency (Fig. 1). Bone loss that contributed little to proximal support of the humeral component was considered grade $1 .{ }^{12}$ Bone loss extending to the metaphysis and thus potentially compromising rotator cuff insertion was considered grade 2 , and bone loss that extended into the diaphysis was grade 3 .

The most recent follow-up radiographs were analysed for radiolucencies around the boxplate screws as evi- dence of loosening and for humeral stem loosening, inferior glenoid notching, and incongruence.

Statistical analyses. Pain and function scores and range of movement were compared pre- and post-operatively by an independent statistician (who was not an author) using a paired $t$-test. A Fisher's exact test was used to analyse the effect of severe bone loss on the frequency of device-related complications (MedCalc software, Mariakerke, Belgium). A p-value $<0.05$ was considered statistically significant. 
Table III. Summary of literature on reverse shoulder prosthesis used in revision surgery to treat failed hemiarthroplasty

\begin{tabular}{|c|c|c|c|c|c|c|}
\hline \multirow[b]{2}{*}{ Authors } & \multirow[b]{2}{*}{ Number } & \multirow[b]{2}{*}{ Disorder } & \multirow[b]{2}{*}{$\begin{array}{l}\text { Mean follow-up } \\
\text { (months) }\end{array}$} & \multirow[b]{2}{*}{$\begin{array}{l}\text { Active eleva- } \\
\text { tion (pre/post) }\end{array}$} & \multicolumn{2}{|l|}{ Constant } \\
\hline & & & & & $\begin{array}{l}\text { ASES }^{\dagger} \text { scores (pre/ } \\
\text { post) }\end{array}$ & $\begin{array}{l}\text { Re-operation } \\
\text { rate (\%) }\end{array}$ \\
\hline DeWilde et al ${ }^{17}$ & 5 & $\begin{array}{l}3 \text { failed hemiarthroplasty for CTA } \\
1 \text { failed hemiarthroplasty for fracture } \\
1 \text { failed hemiarthroplasty with antero- } \\
\text { superior subluxation }\end{array}$ & 30 (23 to 39$)$ & Fair & $14 / 62$ & 20 \\
\hline Delloye et al ${ }^{16}$ & 5 & $\begin{array}{l}4 \text { failed hemiarthroplasty } \\
1 \text { primary CTA }\end{array}$ & $81(66$ to 96$)$ & $\mathrm{Na}^{\S} / 72$ & $\mathrm{Na} / 40$ & 60 \\
\hline Boileau et $\mathrm{al}^{9}$ & $45^{\ddagger}$ & $\begin{array}{l}21 \text { primary CTA } \\
5 \text { sequela of fracture } \\
19 \text { failed hemiarthroplasty }\end{array}$ & $40^{\ddagger}(24$ to 72$)$ & $55 / 121^{\ddagger}$ & $17 / 59^{\ddagger}$ & $\begin{array}{l}13 \text { overall }^{\ddagger} \\
42 \text { of revisions }\end{array}$ \\
\hline Frankle et al (2006) & 19 & 19 failed hemiarthroplasty for CTA & 44 (24 to 89 ) & $50 / 76$ & $29 / 61$ & 32 \\
\hline Werner et $\mathrm{al}^{15}$ & 21 & $\begin{array}{l}15 \text { failed hemiarthroplasty for fracture } \\
5 \text { failed TSR } \\
1 \text { failed hemiarthroplasty for OA }\end{array}$ & 38 & $39 / 96$ & $25 / 55$ & 38 \\
\hline
\end{tabular}

\section{Results}

Pre- and post-operative clinical assessment. The clinical results, including the American Shoulder and Elbow Surgeons scores and the VAS scores as well as the ranges of movement, are summarised in Table I. No patient had pre-operative evidence of loosening of the hemiarthroplasty. The mean follow-up was 44 months (24 to 89). All patients had improvement in their VAS pain score, with a mean improvement from 7.3 (3.5 to 10$)$ to 2.5 (0 to 9) $(\mathrm{p}<0.0001)$. Statistically significant improvements were seen in the mean total American Shoulder and Elbow Surgeons scores (29.1 (10 to 57.5) to 61.2 (17.5 to 95), $\mathrm{p}<0.0001)$, mean VAS function scores $(2.7$ ( 0 to 5$)$ to 5.5 (0 to 10$), p=0.0082)$, mean forward flexion $\left(49.7^{\circ}\left(30^{\circ}\right.\right.$ to $\left.90^{\circ}\right)$ to $76.1^{\circ}\left(0^{\circ}\right.$ to $\left.\left.150^{\circ}\right), \mathrm{p}=0.0062\right)$, and mean abduction $\left(42.2^{\circ}\left(0^{\circ}\right.\right.$ to $\left.60^{\circ}\right)$ to $77.2^{\circ}\left(30^{\circ}\right.$ to $\left.\left.150^{\circ}\right), \mathrm{p}=0.0005\right)$. Patient satisfaction was seen in 15 shoulders $(79 \%) ; 13(68 \%)$ rated their outcome as good or excellent. There were four dissatisfied patients.

Pre-operative radiographs. As seen in Table II, 17 shoulders $(89 \%)$ had moderate to severe incongruence in joint position (seven superior, nine anterosuperior, and one posterior). Moderate to severe peripheral erosion of the glenoid was seen in 13 shoulders (68\%). Moderate to severe erosion of the acromion was seen in eight shoulders (42\%). Three patients (16\%) had acromial fractures.

Initial post-operative radiographs. Proximal humeral bone loss was seen in 11 shoulders (58\%). There was one patient with severe bone loss (grade 3), six with moderate (grade 2) and four patients with mild (grade 1).

Final follow-up radiographs. These studies were performed at a mean of 38 months ( 6 to 85 ) after the initial reverse shoulder prosthesis reconstruction and include the most recent radiographs of all patients (including those requiring revision).
Complications. These were either prosthesis related or nonprosthesis related. Six shoulders $(32 \%)$ had prosthesisrelated complications. Two patients had failure of the polyethylene. One of these had grade 2 and the other grade 3 humeral bone loss. Both were treated with revision of the polyethylene component. One was also treated with an allograft to reconstruct the severe proximal humeral bone loss.

One patient fell and sustained a peri-prosthetic fracture of the humerus with humeral loosening. This patient was revised using a longer humeral stem. One patient sustained a peri-prosthetic scapular fracture who was treated nonoperatively due to medical contraindications and remains dissatisfied. A further patient underwent revision to an EPOCA Constrained Glenoid (Argomedical USA Inc., Redondo Beach, California) owing to loosening of the glenoid baseplate with a peri-prosthetic scapular fracture and remains dissatisfied. Finally, there was one patient who had baseplate loosening with migration of the glenosphere as well as humeral loosening whose symptoms were not such as to require revision. There were no other cases of baseplate or humeral stem loosening, and no other cases demonstrating radiolucent lines. There were no cases of scapular notching.

All three patients with glenoid-related complications had severe glenoid bone loss.

Five of the shoulders with prosthesis-related complications had either severe bone loss of the glenoid or grade 3 humeral bone loss, as noted on the initial post-operative radiographs. The other complication related to the prosthesis occurred in a shoulder with moderate bone loss. In patients with no or only minimal bone loss there were no prosthesis-related complications. The rate of prosthesisrelated complications was significantly higher in patients with severe bone loss $(\mathrm{p}=0.0072)$. 


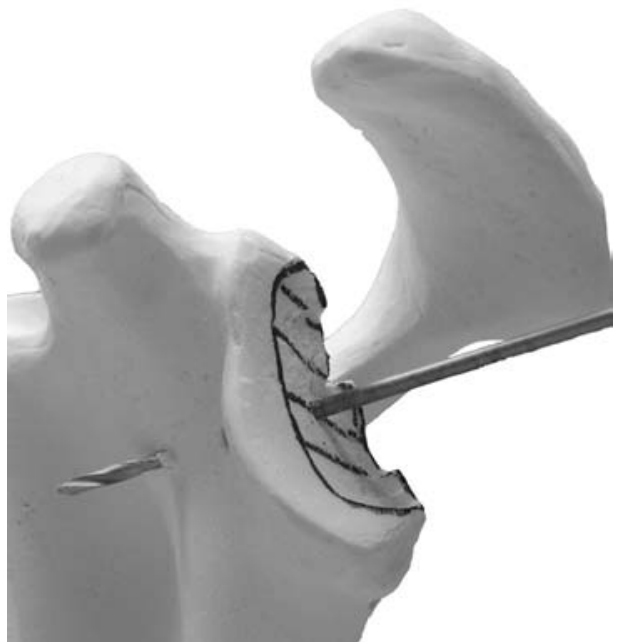

Fig. 1a

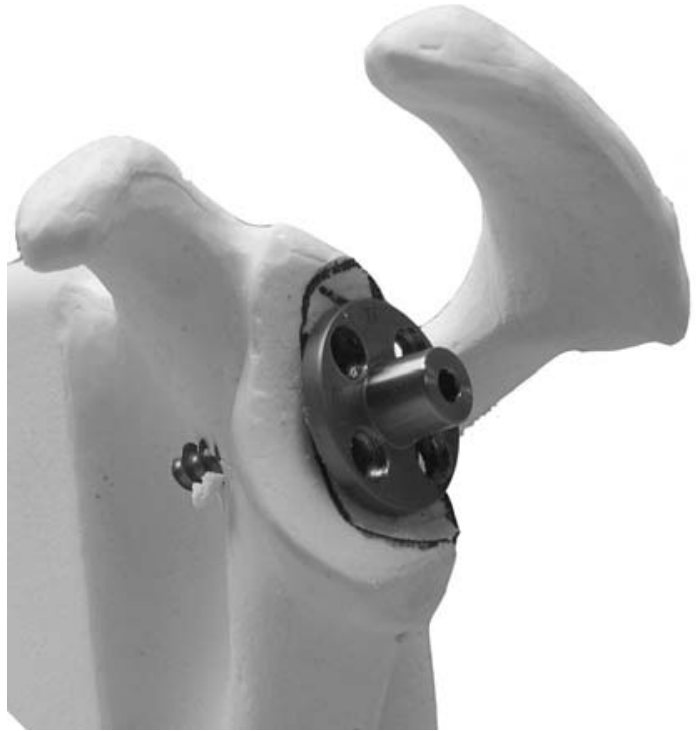

Fig. 1b

Improper placement of a) the drill and b) the baseplate in a case of severe posterior gleniod bone loss. Placement of the baseplate in this orientation results in poor fixation with minimal purchase of the baseplate onto the gleniod bone.

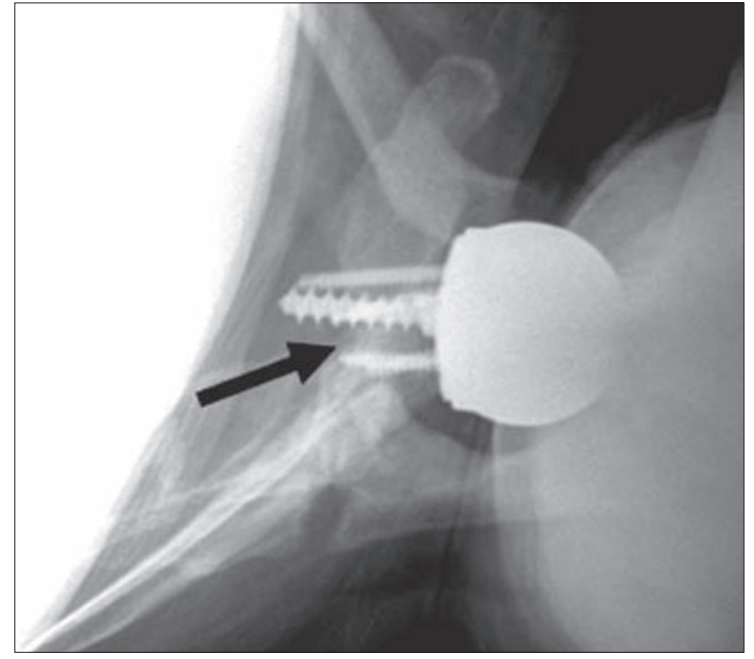

Fig. 2a

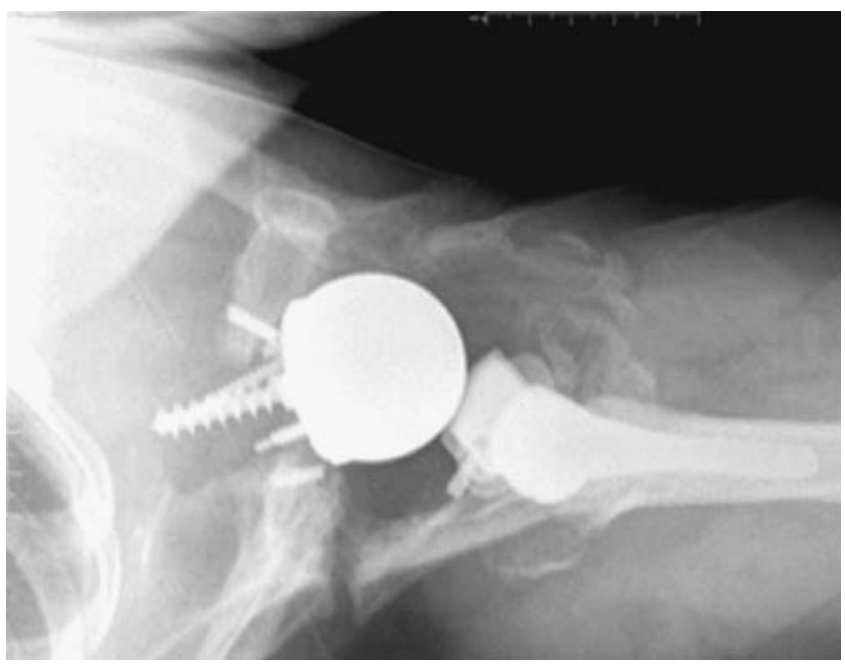

Fig. $2 b$

Axillary radiographs of the reverse shoulder prosthesis showing a) the incorrect placement of glenosphere created a stress riser (arrow) in the scapula and b) with the subsequent development of a peri-prosthetic scapular fracture.

Overall, six shoulders (32\%) required re-operation, four of which $(21 \%)$ required revision.

Three shoulders $(16 \%)$ had complications which were not related to the prosthesis. A patient with a post-operative infection and another with a post-operative haematoma were treated with irrigation and debridement. Finally, one patient with painful hardware from fixation of an acromial fracture elected not to have her hardware removed.

At the most recent follow-up there were four dissatisfied patients. Both patients with peri-prosthetic scapular fractures were dissatisfied with their outcome. Additionally, two patients did not achieve expected improvements in pain and function, despite improvements in their pain and function scores.

\section{Discussion}

The treatment of patients with glenohumeral arthritis in the presence of severe rotator cuff deficiency is difficult and total shoulder replacement in these patients met with early failures, as eccentric loads placed on the glenoid component result in its loosening. ${ }^{13,14}$ This has prompted surgeons to choose humeral hemiarthroplasty in this situation. Despite 
becoming the treatment of choice for these patients, ${ }^{1-6}$ variable gains in functional range of movement and inconsistent improvements in pain have been observed. ${ }^{1,2,4-6}$ Also, some patients develop progressive bone loss of the glenoid and instability. ${ }^{9}$

To date, there has been no reliable salvage treatment for these patients. The primary goal of revision arthroplasty for patients in this study was pain relief. As noted in Table I, this goal was achieved in all patients, with improvement in the mean VAS pain score and all functional scores at a mean of 44 months' follow-up. However, four patients remained dissatisfied.

Although the reverse design has been used successfully to treat primary glenohumeral arthritis associated with severe rotator cuff deficiency, ${ }^{9,10,15}$ using the reverse design in the revision setting has been fraught with complications (Table III). ${ }^{9,15-17}$ Delloye et $\mathrm{al}^{16}$ reported that three of five patients, and DeWilde et $\mathrm{al}^{17}$ noted that one of five patients treated for failed hemiarthroplasty required further revision. $^{2}$ In a larger series, Boileau et $\mathrm{al}^{9}$ reported that $42 \%$ of patients ( 8 of 19) required re-operation after conversion of a failed hemiarthroplasty to a reverse prosthesis. In this series, a similarly high rate of complications was seen. These complications were related to severe pre-operative bone loss of the glenoid and proximal humerus.

Progressive erosion of the glenoid by a humeral hemiarthroplasty can produce pain and reduce the amount of bone available for prosthetic attachment. In the current series, 13 patients $(68 \%)$ had moderate to severe glenoid erosion following hemiarthroplasty. This renders stable fixation of the baseplate extremely difficult. In this series, the three glenoid component complications were encountered in the presence of severe glenoid bone loss. Two patients sustained peri-prosthetic scapular fractures, and one developed baseplate loosening with migration of the glenosphere. In one of these patients the bone loss was primarily posterior (down to the level of the scapular spine), producing a severely retroverted glenoid with bone remaining only anteriorly on the glenoid neck. In an attempt to prevent additional bone loss from reaming, the baseplate was placed in a retroverted position (Fig. 1). Unfortunately, this produced a stress riser between the spine of the scapula and the central screw, resulting in a periprosthetic fracture (Fig. 2). From this experience, in cases of severe posterior glenoid bone loss we currently place the central screw into the base of the scapular spine and place bone graft under the baseplate. Pre-operative CT scans are now performed on all patients to assist in planning the appropriate placement of the baseplate.

Proximal humeral bone loss was also related to an unsatisfactory outcome. In this series, there were two patients with polyethylene failure requiring revision who had grade 2 and grade 3 proximal humeral bone loss, respectively. Moderate to severe peripheral erosion of the glenoid was seen in 13 shoulders $(68 \%)$. Moderate to severe erosion of the acromion was seen in eight shoulders $(42 \%)$. At the latest follow-up, both patients rated their outcome as excellent. As the reverse articulation is semi-constrained, increased rotational, translational and frictional forces are transmitted to the humeral side of the arthroplasty. Based on the observations from this study, modifications have been made in both prosthesis design and surgical technique in an effort to minimise mechanical failure. Currently, the polyethylene component is supported by a proximal metal shell rather than the previously used small metal button that attached the polyethylene socket to the stem. In addition, we often reconstruct grade 3 proximal humeral bone loss with allograft to re-establish cortical support. Results following these changes are not yet available.

To our knowledge, patients with pain and loss of function after failure of a hemiarthroplasty used for glenohumeral arthritis in the presence of severe rotator cuff deficiency have had no surgical treatment options available. The use of the reverse shoulder prosthesis can provide improvements in pain and function. However, high rates of complication were seen which were related to local bone loss. Recognition of such bone loss is necessary to enable a successful reconstruction and limit complications.

\section{Supplementary Material}

ё A further opinion by $\mathrm{Mr}$ Joaquin Sanchez-Sotelo is available with the electronic version of this article on our website at www.jbjs.org.uk

We would like to thank Tony S. Keller, PhD for his statistical support.

The author or one or more of the authors have received or will receive benefits for personal or professional use from a commercial party related directly or indirectly to the subject of this article. In addition, benefits have been or will be directed to a research fund, foundation, educational institution, or other nonprofit organisation with which one or more of the authors are associated.

\section{References}

1. Arntz CT, Kackins S, Matsen FA 3rd. Prosthetic replacement of the shoulder for the treatment of defects in the rotator cuff and the surface of the glenohumeral joint. J Bone Joint Surg [Am] 1993;75-A:485-91.

2. Field LD, Dines DM, Zabinski SJ, Warren RF. Hemiarthroplasty of the shoulder for rotator cuff arthropathy. J Shoulder Elbow Surg 1997;6:18-23.

3. Pollock RG, Deliz ED, Mcllveen SJ, Flatow EL, Bigliani LU. Prosthetic replacement in rotator cuff-deficient shoulders. J Shoulder Elbow Surg 1992;1:173-86

4. Williams GR Jr, Rockwood CA Jr. Hemiarthroplasty in rotator cuff-deficient shoulders. J Shoulder Elbow Surg 1996;5:362-7.

5. Zuckerman JD, Scott AJ, Gallacher MA. Hemiarthroplasty for cuff tear arthropathy. J Shoulder Elbow Surg 2000;9:169-72.

6. Sanchez-Sotelo J, Cofield RH, Rowland CM. Shoulder hemiarthroplasty for glenohumeral arthritis associated with severe rotator cuff deficiency. J Bone Joint Surg [Am] 2001;83-A:1814-22

7. Lohr JF, Cofield RH, Uhthoff HK. Glenoid component loosening in cuff tear arthropathy. J Bone Joint Surg [Br] 1991;73-B(Suppl II):106.

8. Cofield RH. Total shoulder arthroplasty with the Neer prosthesis. J Bone Joint Surg [Am] 1984;66-A:899-906

9. Boileau P, Watkinson DJ, Hatzidakis AM, Balg F. Grammont reverse prosthesis: design, rationale and biomechanics. J Shoulder Elbow Surg 2005;14(1 Suppl):147-61.

10. Frankle M, Siegal S, Pupello D, et al. The reverse shoulder prosthesis for glenohumeral arthritis associated with severe rotator cuff deficiency: a minimum two-year follow-up study of sixty patients. J Bone Joint Surg [Am]2005;87-A:1697-705.

11. Richards RR, An KN, Bigliani LU, et al. A standardized method for the assessment of shoulder function. J Shoulder Elbow Surg 1994;3:347-52.

12. Antuna SA, Sperling JW, Cofield RH, Rowland CM. Glenoid revision surgery after total shoulder arthroplasty. J Shoulder Elbow Surg 2001;10:217-24. 
13. Barrett WP, Franklin JL, Jackins SE, Wyss CR, Matsen FA 3rd. Total shoulder arthroplasty. J Bone Joint Surg [Am]1987;69-A:865-72.

14. Franklin JL, Barrett WP, Jackins SE, Matsen FA 3rd. Glenoid loosening in total shoulder arthroplasty: association with rotator cuff deficiency. J Arthroplasty 1988;3:39-46.

15. Werner CM, Steinmann PA, Gilbart M, Gerber C. Treatment of painful pseudoparesis due to irreparable rotator cuff dysfunction with the Delta III reverse-ball-and-socket total shoulder prosthesis. J Bone Joint Surg [Am]2005;87-A:1476-86.
16. Delloye C, Joris D, Colette A, Eusier A, Dubuc JE. Mechanical complications of total shoulder inverted prosthesis. Rev Chir Orthop Reparatrice Appar Mot 2002;88:410-14 (in French).

17. DeWilde L, Mombert $\mathbf{M}$, Van Petegem $\mathbf{P}$, Verdonk R. Revision of shoulder replacement with a reversed shoulder prosthesis (Delta III): report of five cases. Acta Orthop Belg 2001;67:348-53 